\title{
Reverse signalling of membrane TNF in human natural killer cells: a comparison of the effect of certolizumab pegol and other anti-TNF agents
}

\author{
Gianluca Fossati, Andrew M Nesbitt \\ From 6th European Workshop on Immune-Mediated Inflammatory Diseases \\ Nice, France. 23-25 November 2011
}

\section{Introduction}

Differences have been seen among the anti-TNFs in mediating reverse signalling of membrane TNF- $\alpha$ $(\mathrm{mTNF}-\alpha)$. Natural killer (NK) cells express high levels of mTNF- $\alpha$ and may be involved in rheumatoid arthritis pathogenesis. We examined the effect of certolizumab pegol (CZP) and the other anti-TNFs, adalimumab (ADA), etanercept (ETA) and infliximab (IFX), on cellular activities of NK cells.

\section{Methods}

Peripheral blood mononuclear cells from healthy volunteers were isolated and incubated in the presence of $100 \mathrm{U} / \mathrm{mL}$ recombinant human (rh) interleukin-2 (IL-2) for $20 \mathrm{~h}$ and $10 \mu \mathrm{g} / \mathrm{mL}$ anti-TNF agents or isotypic controls (human $\operatorname{IgG}_{1 \mathrm{k}}$ and Fab' PEG) for a further $4 \mathrm{~h}$. Antibody-dependent cellular cytotoxicity (ADCC) was measured by loss of cell membrane integrity, by binding of 7-amino-actinomycin D to DNA. For analysis of soluble cytokine production and $\beta$-hexosaminidase release as an index of cell degranulation, NK cells were incubated with rhIL-2 and anti-TNF agents. The concentration of the soluble cytokine interferon- $\gamma$ (IFN- $\gamma$ ) was determined by enzyme-linked immunosorbent assay. $\beta$-hexosaminidase release was quantified upon enzymatic cleavage of 4methylumbelliferyl $\mathrm{N}$-acetyl $-\beta$ - $\mathrm{D}$-glucosaminide in citrate buffer (0.1 M, pH 4.5) by spectrophotometric analysis.

\section{Results}

When NK cells were incubated with anti-TNF agents in the presence of rhIL-2, IFN- $\gamma$ production was significantly increased from the control level of $\sim 84 \mathrm{pg} / \mathrm{mL}$ to $\sim 1.1 \mathrm{ng} / \mathrm{mL}$. All 4 anti-TNF agents stimulated NK cell degranulation, as measured by $\beta$-hexosaminidase levels, to a level of $\sim 27 \%$ degranulation compared with a control level of $3 \%$. ADCC measured in NK cells was detectable only with ADA, ETA and IFX (44.3\%, 46.4\% and $47.9 \%$, respectively) and not with CZP (1\%).

\section{Conclusion}

Anti-TNF agents may result in increased NK cellmediated cytotoxicity by promoting the release of multiple cytotoxic effector molecules and inflammatory cytokines via reverse signalling through constitutively expressed mTNF- $\alpha$. CZP can activate NK cells but, in contrast to conventional anti-TNFs, does not mediate ADCC due to its unique structure (lacking an Fc region).

Published: 23 November 2011

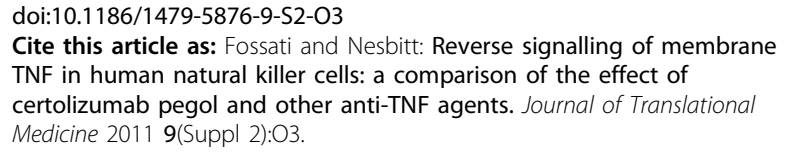

Cite this article as: Fossati and Nesbitt: Reverse signalling of membrane TNF in human natural killer cells: a comparison of the effect of certolizumab pegol and other anti-TNF agents. Journal of Translational Medicine 2011 9(Suppl 2):O3. 